\title{
Evaluating antimicrobial and antioxidant capacity of endemic Phlomis russeliana from Turkey and its antiproliferative effect on Human Caco-2 Cell Lines
}

\author{
MERVE ALPAY ${ }^{1}$, GORKEM DULGER $^{2}$, IBRAHIM E. SAHIN ${ }^{1}$ and BASARAN DULGER ${ }^{3}$ \\ ${ }^{1}$ Department of Biochemistry, Faculty of Medicine, Duzce University, 81620, Duzce, Turkey \\ ${ }^{2}$ Department of Medical Biology, Faculty of Medicine, Duzce University, 81620, Duzce, Turkey \\ ${ }^{3}$ Department of Biology, Faculty of Science, Duzce University, 81620, Duzce, Turkey \\ Manuscript received on June 28, 2018; accepted for publication on September 12, 2018
}

\begin{abstract}
How to cite: ALPAY M, DULGER G, SAHIN IE AND DULGER B. 2019. Evaluating antimicrobial and antioxidant capacity of endemic Phlomis russeliana from Turkey and its antiproliferative effect on Human Caco-2 Cell Lines. An Acad Bras Cienc 91: e20180404. DOI 10.1590/0001-3765201920180404.
\end{abstract}

\begin{abstract}
In this study, the antimicrobial, antioxidant and antitumor activity of ethanol extracts obtained from Phlomis russeliana (Sims.) Lag. ex Benth. (Lamiaceae) were evaluated. Disc diffusion and microdilution methods were used to test the extracts for antimicrobial activity against seven bacteria strains (Bacillus cereus ATCC 7064, Bacillus subtilis ATCC 6633, Staphylococcus aureus ATCC 6538P, Escherichia coli ATCC 10538, Proteus vulgaris ATCC 6899, Salmonella typhimurium CCM 5445 and Pseudomonas aeruginosa ATCC 27853) and four yeast strains (Kluyveromyces fragilis ATCC 8608, Rhodotorula rubra ATCC 70403, Debaryomyces hansenii DSM 70238 and Candida albicans ATCC 10239). Notably, they were more effective against the yeast strains than the bacterial strains. Of the yeast cultures, $D$. hanseii was among the most susceptible, having an inhibition zone of $16.2 \mathrm{~mm}$ with minimum inhibitory concentrations (MICs) and minimum fungicidal concentrations (MFCs) of 64(128) $\mu \mathrm{g} / \mathrm{ml}$, respectively. For cytotoxic determination, Caco-2 cells were cultured as per ATCC protocol, and were treated with $\log$ concentrations $(5-80 \mathrm{mg} / \mathrm{ml})$ of $P$. russeliana. The potency of cell growth inhibition for each extract was expressed as an IC50 value. Moreover, oxidant capacity was evaluated via TOC assay. This product induced antiproliferative activity of $31.33 \%$ at $40 \mathrm{mg} / \mathrm{ml}$ and $20.96 \%$ at $80 \mathrm{mg} / \mathrm{ml}$, without toxic effects on cells, although the oxidant capacity was decreased to $27.06 \pm 0.7 \mathrm{~nm}$ in the $80 \mathrm{mg} / \mathrm{ml}-$ applied group compared to $47.9 \pm 1.8 \mathrm{~nm}$ in the untreated one. Advanced pharmacological studies are needed to further evaluate $P$. russeliana for distinctive features.
\end{abstract}

Key words: Phlomis russeliana, antioxidant activity, cytotoxic effect, antimicrobial activity, endemic plant.

\section{INTRODUCTION}

The use of plants in the treatment of various diseases is an ancient practice that is widespread in many parts of the World (Masika et al. 2000). More than 100 species of the genus Phlomis are

Correspondence to: Basaran Dulger

E-mail: basarandulger@gmail.com

ORCid: http://orcid.org/0000-0002-3184-2652 distributed throughout Eurasia and North Africa, and 34 of the 52 taxa are endemic to Turkey (Cali 2016). The Phlomis species found in Turkey are used as herbal teas, tonics, carminatives, appetizers and stimulants in traditional folk medicine and recognized by local names as ballık otu, calba or şalba (Baytop 1999). Phlomis russeliana (Sims.) Lag.ex Benth. (Lamiaceae), commonly called 
Turkish sage or Jerusalem sage, is endemic to Turkey (Dadandi 2002). During routine field excursions, it was found that this plant is used in the treatment of stomach disorders. The present study aimed to investigate the activity of this endemic plant on the cells, and especially determining the effect of cell proliferation at the beginning cancer mechanism deeply. Colon cancer was selected for the study because of its high incidence. Indications are that further detailed studies are need to clarify the efficacy of this plant.

\section{MATERIALS AND METHODS}

\section{PLANTS EXTRACTION PREPARATION}

Aerial parts of the plant were collected from Golyaka (Duzce Province), Turkey, during the flowering stage in July, 2017. The extraction was performed as described previously by Dulger et al. with some modifications (Dulger et al. 2017). The extract was filtered and the filtrate solvent was evaporated under vacuum using a rotary evaporator at $55{ }^{\circ} \mathrm{C}$ (yield: $14.12 \%$ for ethanol). The resulting dried extract was labelled and stored in sterile screw-capped bottles at $-20^{\circ} \mathrm{C}$. Around 2 $\mathrm{g}$ of the extract was dissolved in $0.1 \mathrm{ml}$ of dimethyl sulfoxide (DMSO) $(5 \mathrm{mg} / \mathrm{ml})$ before testing.

\section{TEST MICROORGANISMS}

The in vitro antimicrobial studies were carried out with seven bacteria strains (Bacillus cereus ATCC 7064, Bacillus subtilis ATCC 6633, Staphylococcus aureus ATCC 6538P, Escherichia coli ATCC 10538, Proteus vulgaris ATCC 6899, Salmonella typhimurium CCM 5445 and Pseudomonas aeruginosa ATCC 27853) and four yeast strains (Kluyveromyces fragilis ATCC 8608, Rhodotorula rubra ATCC 70403, Debaryomyces hansenii DSM 70238 and Candida albicans ATCC 10239) obtained from the Microbiology Research Laboratory of the Duzce University Department of Biology.

\section{DISC DIFFUSION METHOD}

The disc diffusion method was employed (Collins et al. 1987). Sterile 6-mm discs were impregnated with $50 \mu \mathrm{l}$ of the plant extracts. The bacterial cultures were inoculated into Nutrient Broth (Oxoid) and incubated for $24 \mathrm{~h}$ at $37 \pm 0.1{ }^{\circ} \mathrm{C}$, while the yeast cultures were inoculated into Malt Extract Broth (Oxoid) and incubated for $48 \mathrm{~h}$ at 28 $\pm 0.1{ }^{\circ} \mathrm{C}$. The counts of bacterial cultures and yeast cultures were adjusted to $0.5 \mathrm{McF}$ arland standard. Adequate amounts of Mueller Hinton Agar (Oxoid) were dispensed onto sterile plates under aseptic conditions. The test microorganisms $(0.1 \mathrm{ml})$ were inoculated onto the surface of the appropriate solid media on the plates. The agar plates inoculated with the test microorganisms were incubated for $1 \mathrm{~h}$ before placing the extract-impregnated paper discs on the plates. The bacterial plates were then incubated at $37 \pm 0.1{ }^{\circ} \mathrm{C}$ for $24 \mathrm{~h}$ and the yeast plates were incubated at $28 \pm 0.1{ }^{\circ} \mathrm{C}$ for 48 h. After incubation, the inhibition zones formed on the plates were evaluated in $\mathrm{mm}$. Penicillin, Tobramycin, Ampicillin, Nystatin, Clotrimazole and Ketoconazole were used as positive controls.

\section{MICRODILUTION METHOD}

Determination of the minimum inhibitory concentration (MIC) was carried out according to the methods described by Zgoda and Porter with some modifications (Zgoda and Porter 2001). Dilution series $(10-0.5 \mathrm{mg} / \mathrm{ml})$ of the extracts were prepared in test tubes and then transferred to the broth in 96-well microtiter plates. Final concentrations in the medium ranged from 1000 to $50 \mu \mathrm{g} / \mathrm{ml}$. Before inoculation, the bacteria strains and yeast strains were adjusted to $0.5 \mathrm{McF}$ arland and diluted 1:1000 in Mueller Hinton Broth (Oxoid) and Malt Extract Broth (Oxoid), respectively. The plates were incubated at $35^{\circ} \mathrm{C}$ for $18-24 \mathrm{~h}$ for bacteria and at $30^{\circ} \mathrm{C}$ for $48 \mathrm{~h}$ for the yeast cultures. The MIC values of the extracts were defined as the 
lowest concentration that showed no growth, and the minimum bactericidal concentration (MBC) and minimum fungicidal concentration (MFC) were determined by seeding the samples from the clear wells onto Mueller Hinton agar and Malt Extract Agar, respectively. The MBC and MFC were defined as the lowest concentrations yielding negative subcultures. Ampicillin and streptomycin were used as standard antibacterial agents, whereas nystatin was used as the standard antifungal agent. Their dilutions in the microtiter plates were prepared in concentrations of $128-0.25 \mu \mathrm{g} / \mathrm{ml}$.

\section{CELL CULTURE}

The human colon cancer cell line Caco-2 (ATCC number: HTB37) used for the study is well to moderately differentiated, aggressive, microsatellite unstable and epithelial growth factor-dependent. The cells were maintained according to standard cell culture protocol. The colon cancer line was cultured in confluent clusters for application.

\section{CYTOTOXIC ACTIVITY AND MEASUREMENT OF OXIDANT CAPACITY}

In order to assess cellular function, the cells were seeded in equal volumes of $5 \times 10^{4}$ cells $/ 100 \mu \mathrm{l}$ in each well of 96-well plates. The MTT cell proliferation assay was conducted after the Caco-2 cells were plated for $24 \mathrm{~h}$. The cultures were treated with $P$. russeliana dissolved in $(5 \mathrm{mg} / \mathrm{ml}) \mathrm{EtOH}$ (ethanol) at concentrations of 5, 10, 20, 40 and $80 \mathrm{mg} / \mathrm{ml}$ and the control (EtOH in DMEM) were prepared with $0.5 \%$ of Ethanol and Dulbecco's Modified Eagle's Medium (DMEM). They were analysed via colorimetric MTT assay to determine the IC50 (Alpay 2017). Metabolically active cells were determined according to MTT procedure at 540 nm density (Alpay 2017). At the same time, trypan blue assay was performed for each group in order to corroborate the MTT data (Bioresearch, Lonza). The total oxidant status (TOS) was then measured, respectively (Rel Assay Diagnostics,Turkey) (Erel 2005). This method uses xylenol orange to measure ferric ions, which is an oxidized form of ferrous ions in an acidic medium. Briefly, reagents were mixed with $35 \mu 1$ samples of $P$. russeliana $+80 \mathrm{mg} /$ $\mathrm{ml}$ application and with samples of the untreated group. The results of the assay are expressed in terms of micromolar hydrogen peroxide equivalent per liter ( $\mu \mathrm{mol} \mathrm{H} 2 \mathrm{O} 2$ Equiv/L). The total oxidant capacity was analysed for comparison of the $P$. russeliana cell oxidant levels.

\section{STATISTICAL ANALYSIS}

Statistical analysis of results were evalulated by using version 2.03 of the Sigma Stat software. Quantitative data were presented as mean and standard error (SE). The statistical difference between the control and the P. russeliana groups was determined by the Student's t test, with $\mathrm{p}<0.05$ considered as significant. However, this significant difference was coincided with the microscopic analysis of cell proliferation rate.

\section{RESULTS AND DISCUSSION}

Herbal medicine has provided a valuable guide to drug discovery throughout the years (Sahranavard et al. 2009). Almost one-third of prescription drugs in the world are derived from plants, and anticancer properties have been indicated in over 3000 plant species (Ghafari 2015). The objective of this study was to evaluate the antimicrobial, antioxidant and antitumor properties of Phlomis russeliana. Investigations on the antimicrobial activity of Phlomis are limited. In one previously study, ethanol and methanol Phlomis extracts exhibited moderate antibacterial activity against S. epidermidis (9 and $8.5 \mathrm{~mm}$, respectively) and $S$. pyogenes $(9.5 \mathrm{~mm})$ (Yildirim 2013). In another study, $P$. russeliana essential oil has tested against common food-borne bacterial pathogens such as E. coli, $P$. aeruginosa, $S$. aureus and $S$. typhimurium (Demirci 2008). The antimicrobial activities of the $P$. russeliana extract against the test 
microorganisms examined in the present study were qualitatively and quantitatively assessed by the presence of inhibition zones, MIC, MBC and MFC (Tables I and II). The ethanol extract of the plant exhibited moderate antimicrobial effects against the test microorganisms, with inhibition zones of 10.0-16.2 mm. Notably, among the bacterial strains, S. typhimurium, with an inhibition zone of $13.2 \mathrm{~mm}$, was more susceptible to the plant extract compared to the standard antibiotic tobramycin. Similarly, with an inhibition zone of $12.4 \mathrm{~mm}$, the extract also showed higher antibacterial activity for S. aureus than tobramycin. The antibacterial effects of the extract against the other bacterial strains were far below those of the antibacterial levels of all the standard antibiotics. D. hansenii was more susceptible to the antifungal effects of the extract compared to the standard antifungal antibiotic clotrimazole, and the effects of the extract were equivalent to those of the antifungal antibiotic nystatin. The other yeast strains were more resistant to the antifungal effects of the extract, which

TABLE I

Disc diffusion results of Phlomis russeliana.

\begin{tabular}{|c|c|c|c|c|c|c|c|}
\hline \multirow[b]{2}{*}{ Microorganisms } & \multirow[b]{2}{*}{ Plant extract } & \multirow[b]{2}{*}{$\mathbf{P}$} & \multirow[b]{2}{*}{ AMP } & \multicolumn{4}{|c|}{ Inhibition zones $(\mathrm{mm}) *$} \\
\hline & & & & TOB & NYS & CLT & KETO \\
\hline Bacillus cereus ATCC 7064 & 10.8 & 14.0 & 17.4 & 16.4 & NT & NT & NT \\
\hline Bacillus subtilis ATCC 6633 & 11.0 & 14.8 & 14.2 & 20.2 & NT & NT & NT \\
\hline Staphylococcus aureus ATCC 6538P & 12.4 & 20.4 & 16.8 & 12.0 & NT & NT & NT \\
\hline Escherichia coli ATCC 10538 & 10.0 & 18.2 & 14.4 & 11.4 & NT & NT & NT \\
\hline Proteus vulgaris ATCC 6899 & 12.8 & 10.8 & 16.2 & 14.8 & NT & NT & NT \\
\hline Salmonella typhimurium CCM 5445 & 13.2 & 14.8 & 14.6 & 11.0 & NT & NT & NT \\
\hline Pseudomonas aeruginosa ATCC 27853 & 11.2 & 10.0 & 12.0 & 13.2 & NT & NT & NT \\
\hline Kluyveromyces fragilis ATCC 8608 & 14.2 & NT & NT & NT & 17.6 & 16.4 & 19.2 \\
\hline Rhodotorula rubra ATCC 70403 & 15.8 & NT & NT & NT & 18.4 & 21.8 & 16.8 \\
\hline Debaryomyces hansenii DSM 70238 & 16.2 & NT & NT & NT & 16.2 & 15.2 & 22.2 \\
\hline Candida albicans ATCC 10239 & 14.4 & NT & NT & NT & 18.2 & 20.2 & 24.0 \\
\hline
\end{tabular}

NT: Not tested; P: Penicillin (10 mcg); AMP: Ampicillin (20 mcg); TOB: Tobramycin (10 mcg); NYS: Nystatin (30 mcg); KETO: Ketocanazole: $(20 \mathrm{mcg})$; CLT: Clotrimazole $(30 \mathrm{mcg})$.

TABLE II

Minimum inhibitory concentration (MIC) of Phlomis russeliana.

\begin{tabular}{|c|c|c|c|c|}
\hline \multirow{3}{*}{ Microorganisms } & \multicolumn{4}{|c|}{ MIC (MBC or MFC) } \\
\hline & \multicolumn{4}{|c|}{ Standards } \\
\hline & $\begin{array}{c}\text { EtOH extract } \\
(\mu \mathrm{g} / \mathrm{ml})\end{array}$ & ST & AMP & NYS \\
\hline Bacillus cereus ATCC 7064 & $1000(>1000)$ & $4.0(4.0)$ & $8.0(8.0)$ & NT \\
\hline Bacillus subtilis ATCC 6633 & $1000(>1000)$ & $0.5(1.0)$ & $1.0(2.0)$ & NT \\
\hline Staphylococcus aureus ATCC 6538P & $500(>1000)$ & $2.0(4.0)$ & $0.25(0.35)$ & NT \\
\hline Escherichia coli ATCC 10538 & $1000(>1000)$ & $4.0(4.0)$ & $32(64.0)$ & NT \\
\hline Proteus vulgaris ATCC 6899 & $500(>1000)$ & $8.0(16.0)$ & $0.5(1.0)$ & NT \\
\hline Salmonella typhimurium CCM 5445 & $500(>1000)$ & $16(32)$ & $2.0(4.0)$ & NT \\
\hline Pseudomonas aeruginosa ATCC 27853 & $1000(>1000)$ & $1.0(2.0)$ & $16.0(32.0)$ & NT \\
\hline Kluyveromyces fragilis ATCC 8608 & $250(>500)$ & NT & NT & $16(16)$ \\
\hline Rhodotorula rubra ATCC 70403 & $128(>500)$ & NT & NT & $16(32)$ \\
\hline Debaryomyces hansenii DSM 70238 & $64(128)$ & NT & NT & $16(32)$ \\
\hline Candida albicans ATCC 10239 & $128(>250)$ & NT & NT & $8(16)$ \\
\hline
\end{tabular}

NT: Not tested; ST: Streptomycin; AMP: Amphicillin; NYS: Nystatin. 
exhibited levels far below those of all the standard antifungal antibiotics.

The ethanoic extract was further tested by microdilution in order to determination the MIC, MBC and MFC values. The lowest MIC and MFC values of the extract were $64(128) \mu \mathrm{g} / \mathrm{ml}$ against $D$. hansenii, followed by C. albicans and R. rubra, which ranged between $128(>250)$ and $128(>500)$ $\mu \mathrm{g} / \mathrm{ml}$, respectively. Notably, the extract showed a potential effect against $K$. fragilis with MIC and MFC values of $250(>500) \mu \mathrm{g} / \mathrm{ml}$. The MIC and $\mathrm{MBC}$ values against bacterial strains were very far below those of the standard antibiotics. These findings showed that the extract was more effective against the yeast strains than the bacterial strains. A weak to moderate MIC $(125->1000 \mu \mathrm{g} / \mathrm{ml})$ was observed in the study mentioned earlier, and the $P$. armeniaca extracts showed no antimicrobial effects against the tested microorganisms (Yildirim 2013). In another study, the ethanol extract of P. fruticasa L. was evaluated against seven bacterial and seven fungal species (Ristic et al. 2000). The essential oils displayed antibacterial activity against $S$. aureus, $E$. coli, B. subtilis, K. pneumoniae and M. luteus and the antifungal activity of the extract was positive against $A$. niger, A. ochraceus, C. cladosporoides, $F$. tricinctum and P. helianthi. Several researchers investigated the antimicrobial activity of methanol, ethanol and ethyl acetate extracts and essential oil of $P$. oppositiflora was investigated against eight bacteria and three fungi via disc diffusion. The methanol, ethanol and ethyl acetate extracts of $P$. oppositiflora showed antibacterial activity with 8-15 mm, 7-11 mm and 9-12 mm inhibition zones, respectively (Toroglu and Cenet 2013). Other researchers revealed that methanol extracts of some Phlomis species (P. bruguieri, P. herba-venti and $P$. olivieri) exhibited antibacterial activity against E. coli, K. pneumoniae, S. aureus, S. sanguis and P. aeruginosa (Amor et al. 2009). Likewise, in that study, the extract exhibited moderate antimicrobial activity against both bacterial and yeast strains, while being more effective against yeast strains than bacterial strains. Consequently, all these studies partially support the present findings. Some studies have found a relationship between the antimicrobial activity and the chemical structures of the most plentiful compounds in the tested plant extracts or essential oils and the researchers have stated that the antimicrobial activity of $P$. russeliana could be based on these compounds (Farag 1989, Deans and Svoboda 1989).

The present results revealed that an aqueous extract of this plant possessed moderate antitumor effects in vitro against Caco-2 cells. A previous study stated that cytotoxic activity of different fractions of $P$. lanceolata showed that the petroleum ether fraction exhibited high cytotoxic activity on HT29, Caco-2, T47D and NIH3T3 cancer cell lines. In all the present experiments, the MTT assay was used to determine the viability of the Caco-2 cells incubated for 24 and $48 \mathrm{~h}$ with the positive control and Phlomis at 5, 10, 20, 40 and $80 \mathrm{mg} / \mathrm{ml}$. The control was taken as $100 \%$ for all time periods, and the other lysates were calculated from the percent values shown in Figure 1. The cell viability results verified the synergistic effect

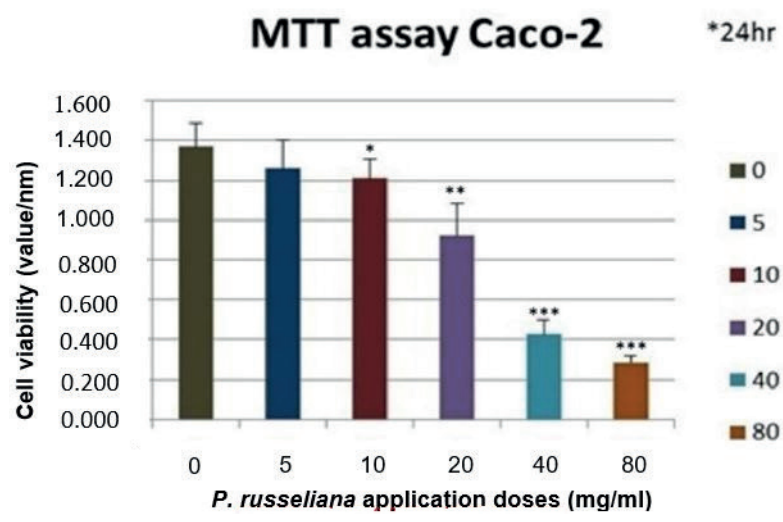

Figure 1 - The effects of different dose P. russeliana treatments with $5 ; 10 ; 20 ; 40 ; 80 \mathrm{mg} / \mathrm{ml}$ on cell viability of colon cancer (Caco-2) cell line. ${ }^{*} \mathrm{p}<0.001$ is $10 \mathrm{mg} / \mathrm{ml}$ concentration through $* * \mathrm{p}<0.00120 ; 40 \mathrm{mg} / \mathrm{ml}$ concentration and $* * * \mathrm{P}<$ 0.001 is $80 \mathrm{mg} / \mathrm{ml}$ treatment concentration as compared to the negative control group up to $24 \mathrm{~h}$ incubation. 
of $P$. russeliana on the proliferation inhibition of the colon cancer. The morphologic survival is shown in Figure 2. The oxidant status of the experimental and control groups was measured by TOS assay. The oxidant status was significantly decreased in the treatment groups, while the antiproliferative effect was observed to be at a significant level (Figure 3). The oxidant capacity was indicated as $27.06 \pm 0.7 \mathrm{~nm}$ at $80 \mathrm{mg} / \mathrm{ml}$ for the treatment group compared to $47.9 \pm 1.8 \mathrm{~nm}$ for the untreated one. The effect of the combined oxidant capacity of $P$. russeliana on cancer cells to counteract reactive oxygen species was analysed. Research studies on some Phlomis species have shown cytotoxic activity against tumour cell lines (Soltani-Nasab et al. 2014). Previously reported findings when correlated with the present results confirmed that many current chemotherapy cancer treatments affect cancer cells. The specific plant phytochemicals responsible for the observed antiproliferative effects are not precisely known at the present time. This encouraging preliminary data on the antiproliferative effects of $P$. russeliana may lead to the development of potential anticancer agents based on such natural wild plants.

\section{CONCLUSIONS}

The present findings showed that $P$. russeliana exhibited possible antioxidant and antimicrobial activity despite cytotoxic activity in colon cancer. In conclusion, in order to utilize the therapeutic agents from the Phlomis species, there is a need for further studies to investigate its safety and molecular mechanism.
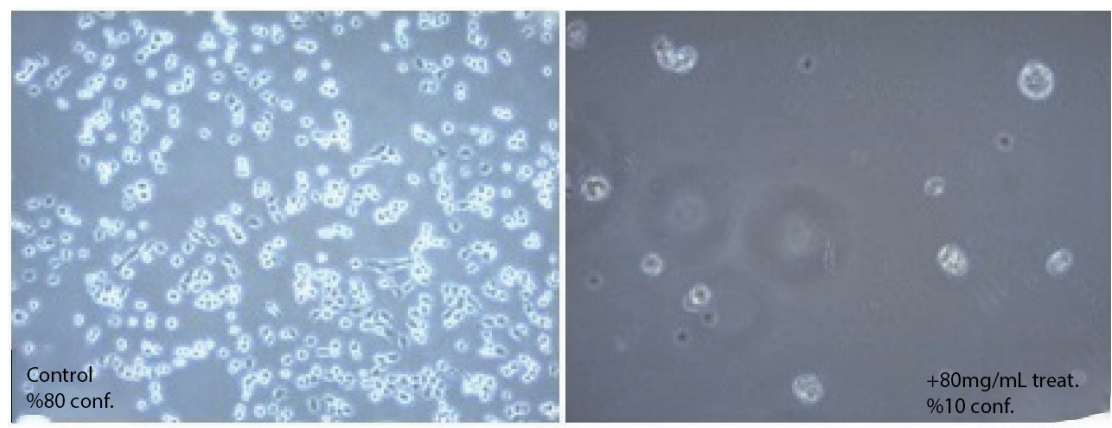

Figure 2 - The role of $P$. russeliana on human colon cancer cells by morphological manner. Cells were compared untreated with $80 \mathrm{mg} / \mathrm{ml}$ of $P$. russeliana (captured from T-25 flask). The difference growth rate log phase between $\% 80-\% 10$ confluency. (displayed inverted microscope x100).

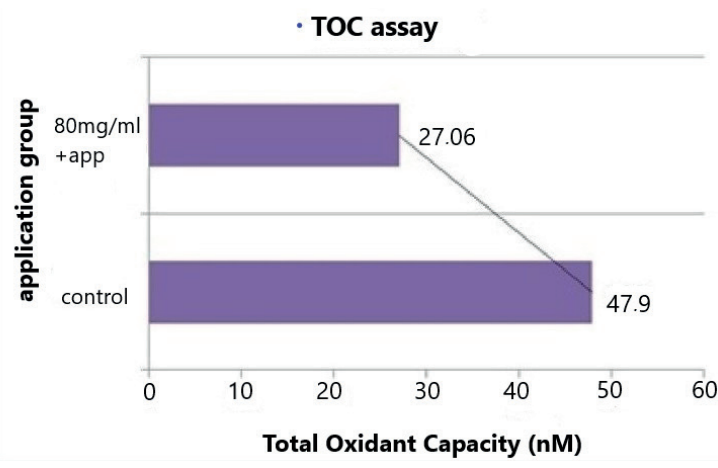

Figure 3 - Quantitative analysis of total oxidant status (TOS) of Caco- 2 cells treated with $80 \mathrm{mg} / \mathrm{ml}$ of $P$. russeliana crosscheck with untreated group up to $48 \mathrm{~h}$ incubation.

\section{AUTHOR CONTRIBUTIONS}

G.D. and M.A. conceived of the presented idea. B.D. developed the theory and performed the computations. G.D and I.E.S. verified the analytical methods. M.A. supervised the findings of this work. All authors discussed the results and contributed to the final manuscript.

\section{REFERENCES}

ALPAY M. 2017. Antioxidant therapy impresses in oxidative stress-induced kidney cells. Bratislava Med J 118(2): 8994. 
AMOR IL, BOUBAKER J, SGAIER MB, SKANDRANI I, BHOURI W, NEFFATI A, KILANI S, BOUHLEL I, GHEDIRA K AND CHEKIR-GHEDIRA L. 2009. Phytochemistry and biological activities of Phlomis species. J Ethnopharmacol 125(2): 183-202.

BAYTOP T. 1999. Therapy with medicinal plants in Turkey (Past and Present). $1^{\text {st }}$ ed., Istanbul, Turkey. Publication of Istanbul University, $320 \mathrm{p}$.

CALI IO. 2016. Anatomy and trichome characteristics of endemic taxon Phlomis russeliana (Sims.) Bentham and their systematic implications. Bangladesh J Botany 45(2): 297-304.

COLLINS CH, LYNE PM AND GRANGE JM. 1987. Microbiological methods. Butter Worths \& Co. Ltd., London, 543 p.

DADANDI MY. 2002. The revision of the Phlomis L. (Lamiaceae) of Turkey. Ph.D. Thesis. Institute of Science and Technology. Ankara: Gazi University.

DEANS SG AND SVOBODA KP. 1989. Antibacterial activity of summer savory (Satureja hortensis L.) essential oil and its constituents. J Hortic Sci 64(2): 205-210.

DEMIRCI F, GUVEN K, DEMIRCI B, DADANDI MY AND BASER KHC. 2008. Antibacterial activity of two Phlomis essential oils against food pathogens. Food Control 19(12): 1159-1164.

DULGER G, TUTENOCAKLI T AND DULGER B. 2017. Anti-Staphylococcal activity of Verbascum thapsus L. against Methicillin-Resistant Staphylococcus aureus. Konuralp Med J 9(1): 53-57.

EREL O. 2005. A new automated colorimetric method for measuring total oxidant status. Clin Biochem 38(12): 1103-1111.

FARAG RS, DAW ZY, HEWEDI FM AND EL-BAROTY GSA. 1989. Antimicrobial activity of some Egyptian spice essential oils. J Food Protect 52(9): 665-667.
GHAFARI S, NAGHIBI F, ESMAEILI S, SAHRANAVARD S AND MOSADDEGH M. 2015. Investigating the cytotoxic effect of some medicinal plants from northern parts of Iran. RJP 2(2): 47-51.

MASIKA PJ, VAN AVERBEKE W AND SONANDI A. 2000. Use of herbal remedies by small scale farmers to treat livestock diseases in the central Eastern Cape Province, South Africa. J S Afr Vet Ass 71(2): 87-91.

RISTIC MD, DULETIC-LAUSEVIC S, KNEZEVICVUKCEVIC J, MARIN DP, SIMIC D, VUKOJEVIC J AND VAJS V. 2000. Antimicrobial activity of essential oils and ethanol extract of Phlomis fruticosa L. (Lamiaceae). Phytother Res 14: 267-271.

SAHRANAVARD S, NAGHIBI F, MOSADDEGH M, ESMAEILI S, SARKHAIL P, TAGHVAEI M AND GHAFARI S. 2009. Cytotoxic activities of selected medicinal plants from Iran and phytochemical evaluation of the most potent extract. Res Pharm Sci 4(2): 133-137.

SOLTANI-NASAB F, ASGARPANAH J, MAJDZADEH M AND OSTAD SN. 2014. Investigating the effect of Phlomis lanceolata Boiss and Hohen on cancer cell lines. Pharmacol Res 52: 333-336.

TOROGLU S AND CENET M. 2013. Comparison of antimicrobial activities of essential oil and solvent extracts of endemic Phlomis oppositiflora Boiss. \& Hausskn. from Turkey. Pak J Zool 45(2): 475-482.

YILDIRIM AB, KARAKAS FP AND TURKER AU. 2013. In vitro antibacterial and antitumor activities of some medicinal plant extracts, growing in Turkey. Asian Pac J Trop Med 6(8): 616-624.

ZGODA JR AND PORTER JR. 2001. A convenient microdilution method for screening natural products against bacteria and fungi. Pharm Biol 39(3): 221-225. 